(pp 90-101)

\title{
The Characteristics of Collocational Patterns in Texts in the Field of Physical Therapy
}

\author{
Shoko MIYAMOTO, PT, MA, Kenzo MIYAMOTO, PT, PhD, Yutaka TAKUMA, PT, PhD, \\ Yoshikazu INOUE, PT, MEd, Hideaki TAKEBAYASHI, PT, PhD, Takao OKABE, PT, MEd, \\ Koji TAKIMOTO, PT, MEd \\ Department of Physical Therapy, Tosa Rehabilitation College \\ Takahiro IOROI, PhD \\ Faculty of Cultural Studies, University of Kochi
}

Purpose: This is an expanded version of the study "Selecting Technical Vocabulary in the Field of Physical Therapy and Determining its Characteristics", which previously appeared in this journal. The aim of this study is to identify the features of English in the field of physical therapy from the viewpoint of collocational patterns.

Method: We examined collocational patterns in the two corpora created for the previous study (RA corpus: 397,874 words, PT text corpus: 546,666 words). The heads of collocation for analysis were combinations of adverb+verb, verb+noun, and adjective+noun. In each head, two-word units which co-occur three times or more were extracted from the two corpora. A mutual information score of the units was calculated to identify whether there are unique collocational patterns which have stronger connections in texts in the physical therapy field. Mutual information shows the expected probability of co-occurrence. The higher score tell us the stronger attraction between the words.

Results: In all heads, there are combinations of two words showing high scores in common across the two corpora.

Conclusion: Knowledge of collocation is vital to improve reading ability. Learning collocational patterns observed in the two corpora will be an effective strategy to increase the speed of understanding physical therapy texts. 